\title{
Article \\ Age-Dependent Enclosure Use in Juvenile Chinese Crocodile Lizards, Shinisaurus crocodilurus crocodilurus
}

\author{
Kimberley C. Carter ${ }^{1, *}$, James J. Hicks ${ }^{2}$, Daniel Kane ${ }^{1}$, Benjamin Tapley ${ }^{1}$ and Christopher J. Michaels ${ }^{1}$ \\ 1 Zoological Society of London, London NW1 4RY, UK; daniel.kane@zsl.org (D.K.); ben.tapley@zsl.org (B.T.); \\ christopher.michaels@zsl.org (C.J.M.) \\ 2 Berkshire College of Agriculture, Maidenhead SL6 6QR, UK; jhicks@bca.ac.uk \\ * Correspondence: kimberley.carter@zsl.org
}

check for updates

Citation: Carter, K.C.; Hicks, J.J.;

Kane, D.; Tapley, B.; Michaels, C.J. Age-Dependent Enclosure Use in Juvenile Chinese Crocodile Lizards, Shinisaurus crocodilurus crocodilurus. J. Zool. Bot. Gard. 2021, 2, 406-415. https://doi.org/10.3390/jzbg2030029

Academic Editor: Kris Descovich

Received: 11 June 2021

Accepted: 19 July 2021

Published: 1 August 2021

Publisher's Note: MDPI stays neutral with regard to jurisdictional claims in published maps and institutional affiliations.

Copyright: (C) 2021 by the authors Licensee MDPI, Basel, Switzerland. This article is an open access article distributed under the terms and conditions of the Creative Commons Attribution (CC BY) license (https:/ creativecommons.org/licenses/by/ $4.0 /)$.

\begin{abstract}
This study compared the resource use of juvenile zoo-living Chinese crocodile lizards, Shinisaurus crocodilurus crocodilurus across three observation windows, spanning nine months, accounting for time of day and lizard age, and under consistent environmental conditions. Lizards showed a significant difference in proportionate resource use, quantified using a modified spread of participation indices between the second and final sampling period, such that with increasing age, resources were more equally utilised. The time of day did not have a significant effect on resource use. Lizards in this study significantly increased their use of water bodies and branches outside the bask zone and decreased their use of the land areas within the bask zones over time. Resource use data suggests the importance of providing enclosures which cater to ontogenetic shifts in captive individuals or within mixed age groupings.
\end{abstract}

Keywords: resource; animal welfare; captive management; niche use

\section{Introduction}

Understanding how individuals of a particular species utilise their enclosures and the resources available to them can help to inform captive management and enclosure design, as well as aiding in assessing animal welfare. One conception of animal welfare is described as how well an animal can cope in its environment [1,2]. Resource utilisation differences between age groups have been documented in several taxa but are not well studied in reptiles [3]. The size of an animal may impact resource utilisation in mixed age captive groups and may constrain juveniles to niches that are not being used by adults, regardless of whether or not it is appropriate for their welfare [4]. The restriction of available resources in wild animals may be influenced by competition, predation, and physiological constraints and tolerances, as well as often complex interactions between these variables $[5,6]$. The availability of environmental resources may have long-term impacts on growth in reptiles; in particular, limited access to heat sources may affect behavioural responses and the speed of biochemical reactions, impacting individual fitness [7-10]. To maintain the best welfare for animals in captivity, enclosure design may need to be adapted to meet the needs of individuals in mixed age groups, prevent the involuntary restriction of resources to certain subsets, and tailor enclosures to the ages of the animals. Furthermore, the management of reptiles in captivity should be based on the natural history of the focal species; therefore, to facilitate this, the best approach to take is the union of field and captive data [11].

The Chinese crocodile lizard Shinisaurus crocodilurus is a semi-aquatic, viviparous, diurnal species of lizard that specialises in occupying fresh water and evergreen broadleaf forests $[12,13]$. They are habitat specialists that exhibit a preference for small, remote streams along mountain ridges, within undisturbed, tropical forest $[12,14,15]$. This species is currently assessed as endangered [16] and is the only living species in the family Shinisauridae. There are two recognised subspecies: S. c. crocodilurus and S. c. vietnamensis [12] This evolutionary distinctiveness coupled with a very restricted range, limited to riparian 
habitats within Southern China and Northern Vietnam, renders this species particularly at risk. Both in situ and ex situ conservation and efforts to expand the current knowledge of the natural history of this species are of high importance for the continued survival of the species $[12,14,15,17]$.

Resource use preferences across ages in Shinisaurus crocodilurus is poorly documented in captivity, although resource partitioning has been shown to vary ontogenetically in other lizards $[18,19]$. However, wild habitat preferences in S. c. vietnamensis showed variation between juveniles and adults; juveniles typically favour low lying ferns, shrubs, and canes with a median height of $\approx 63.5 \mathrm{~cm}$ above water level, while adults perch within densely vegetated branches with a median height of $\approx 119 \mathrm{~cm}$ above water level. Lizards are rarely observed on the forest floor, but utilise refuges such as tree holes, rock shelters, densely vegetated perches, and utilise vertical over horizontal space [15,17]. Wild observations of adult S. c. vietnamensis found that animals are inactive for large proportions of the day; activity begins at sunrise, with peak activity during the morning and noon. However, hours of peak activity were not specified, so the timing of resource use through the day is unknown [17]. If the behaviour of captive lizards reflects that of wild animals, enclosures should be designed to allow equal opportunities to access resources, to benefit mixed age groups or to correlate with preferences as animals age. We assessed whether resource use in juvenile Shinisaurus crocodilurus alters with age, which would have implications for resource provision in captive settings.

\section{Materials and Methods}

Eight Shinisaurus c. crocodilurus animals born between 2 November 2019-25 November 2019, at around $4 \mathrm{~g}$ mass and $150 \mathrm{~mm}$ total length, from two separate females (six juveniles from one female and two from the other) were housed individually in $30 \mathrm{~cm}^{3}$ Exo Terra vivaria (Exo Terra, Alfeld, Germany) with a water depth of c. $6 \mathrm{~cm}$, a land area comprised of cork bark, and branches c. $1 \mathrm{~cm}$ in diameter. Enclosures were furnished as similarly as visually possible, with identical layouts and the cork bark sections also being approximately equal; any differences due to the natural origins of the perching were considered negligible in terms of their utilisation by a lizard. Branch size was considered appropriate for this size, as adult S. c. crocodilurus have been reported to perch on branches with diameters $<1 \mathrm{~cm}$, while adult S. c. vietnamensis perch on branches of mean diameter c. $1.3 \mathrm{~cm}$ and juveniles occupy smaller stemmed canes, ferns, and shrubs [17]. Observations (see below) began on 12 February 2020 (Day 0). Vivarium size was increased to $45 \mathrm{~cm}^{3}$, and branch size was adjusted to branches ranging from c. $2-3 \mathrm{~cm}$ in diameter to cater for the increased size of the lizards on Day 202-215 (corresponding to the last observation period) when animals were around $15 \mathrm{~g}$ in weight. Water depth reached $10-11 \mathrm{~cm}$ in the larger vivaria, with temperatures ranging from $18-23^{\circ} \mathrm{C}$ (night and day ambient temperatures, respectively). A $40 \mathrm{~W}$ incandescent lamp, later changed to an Arcadia $50 \mathrm{~W}$ Solar floodlight and a $6 \%$ Arcadia T5 UV lamp with reflector, provided localised bask zones, ranging between 26-31 ${ }^{\circ} \mathrm{C}$ surface temperature, and ultraviolet index (UVI) across the enclosure of $0-4$. Minimum temperatures of $20.6{ }^{\circ} \mathrm{C}$ (day) and $17.5^{\circ} \mathrm{C}$ (night) on the land area outside of the bask zone were recorded with an infrared thermometer. Room climate control provided ambient temperatures ranging from $18-23^{\circ} \mathrm{C}$. The lighting was adjusted when the animals were roughly 6 months old (between the first and second observation periods); bask temperatures were within the same temperature range between changes. Temperatures throughout the year were consistent, with no extreme seasonal variation. Animals were weighed every month using On Balance Digital Scales (Model: DT-1000; $0.1 \mathrm{~g}$ increments) and were not sexed at any point during the study; sex cannot be reliably distinguished from external morphology [17], and there was insufficient management requirements to justify sexing through invasive veterinary investigation. 
Enclosures were divided into six resources; branches within the bask zone (BB), non-bask zone branches $(\mathrm{BN})$, cork within the bask zone (CB), non-bask zone cork $(\mathrm{CN})$, shorelines of the cork and submerged branches (S), and the water body (W). Resources in this study represent distinct areas which provide different opportunities to thermoregulate. Instantaneous focal sampling of resource use occurred at three time periods; the resource occupied by each lizard was recorded once anytime within the set time periods AM (8:00-11:00), midday (11:01-14:00), and PM (14:01-17:00) daily over three observation periods: days 0-35 (February/March), days 102-136 (May/June), and days 200-219 (August/September) from the start of the study. Instantaneous sampling of all individuals occurred in succession within the same observation periods. Observations were performed live, viewing through the front of the enclosure. This was predominantly performed by one person. However, due to work constraints a small percentage of the observations were performed by other keepers. Instructions on noting observations were given to maintain consistency in recording.

Mean proportionate surface areas for resources were calculated using ImageJ [20] from an image above the enclosure (Figure 1). Overlapping resources were taken into account when measuring, for example the full representative surface area of the water body was measured over the overlapping cork. Modified spread of participation indices (mSPI) [21], allowing for unequal zones, were calculated for each lizard at each time period in each observation period (i.e., a mSPI score was generated for AM, midday, and PM time periods in each of the three observation periods for each lizard). A $\mathrm{mSPI}$ is a measure of evenness of resource use, allowing for inequality of resource sizes; a mSPI value of 0 would indicate the maximum enclosure use, where all zones are used equally relative to size; while a value of 1 indicates that only one area is being utilised (21). A repeated measures ANOVA was performed on the mSPI data using the model $\mathrm{mSPI}=$ ObservationPeriod + TimePeriod + ObservationPeriod $*$ TimePeriod. Data were normally distributed (Shapiro-Wilk test; $p=0.39$ ) and did not violate sphericity (Mauchly's test of sphericity; observation period, $p=0.287$; time period, $p=0.812$; observation period ${ }^{*}$ time period, $p=0.247$ ). Fisher's LSD post hoc tests with bonferroni adjustments for multiple comparisons were then used to compare between treatments for significant variables. A Friedman test for repeated measures was then used to compare mean proportionate resource use (=number of observations in a given resource/total observations) for each lizard for each resource between observation periods. All statistical analyses were performed in SPSS 26.0 for Windows (IBM, Armonk, NY, USA). 


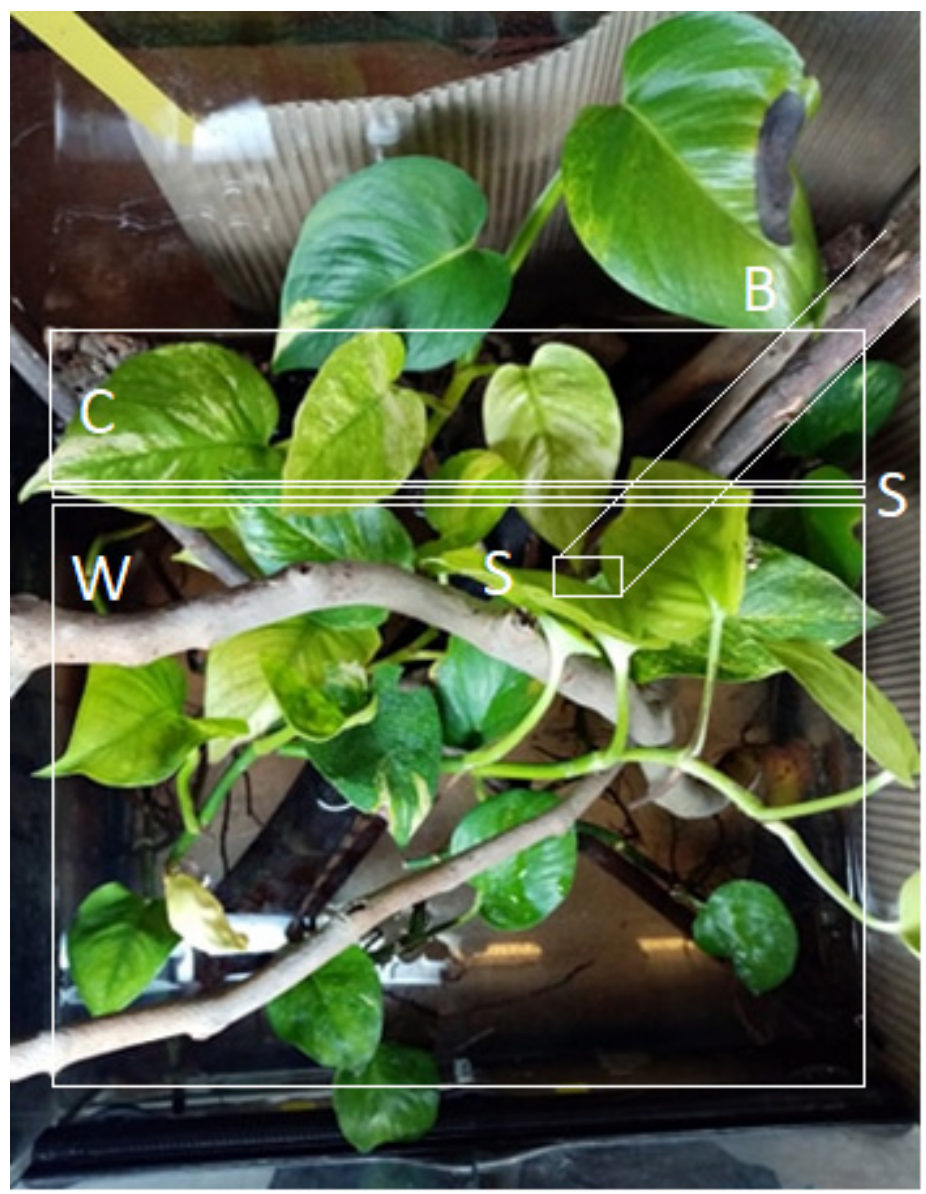

Figure 1. The view from above a typical $45 \mathrm{~cm}^{3}$ Exo Terra vivarium setup, furnished with appropriately sized branches for the animal's size, including live devil's ivy (Epipremnum aureum), and a cork land area $(\mathrm{C})$ with a water body $(\mathrm{W})$ with a depth to the cork land area. Shorelines (S) were recorded where the water body met the cork land area and submerged branches. The branch resource areas (B) were recorded as any above water branch area. Resource areas for the cork and branches were further divided into bask and non-bask resources. More exposed resources in this study were noted as the branches within and outside of the bask zone, the shoreline, and the water body. The cork within and outside of the bask zones were noted as being less exposed, as they were more sheltered from overlying branches and vegetation. Labelled resource areas in this figure are representative and not to scale. Corrugated cardboard outside each vivarium restricted between-vivaria visibility of lizards occupying neighbouring vivaria.

\section{Results}

Mean (SD) proportionate areas for resources were calculated $(\mathrm{BB}=0.020(0.029)$; $\mathrm{BN}=0.089$ (0.005); $\mathrm{CB}=0.023(0.006) ; \mathrm{CN}=0.116(0.011) ; \mathrm{S}=0.059(0.010) ; \mathrm{W}=0.693(0.029)$ ).

The mSPI was significantly affected by observation period $\left(\mathrm{F}_{2,28}=3.895, p=0.045\right)$ but not by time period $\left(F_{2,28}=3.102, p=0.077\right)$ or the interaction between the two $\left(F_{4,28}=0.876\right.$, $p=0.491$ ) (Figure 2). 


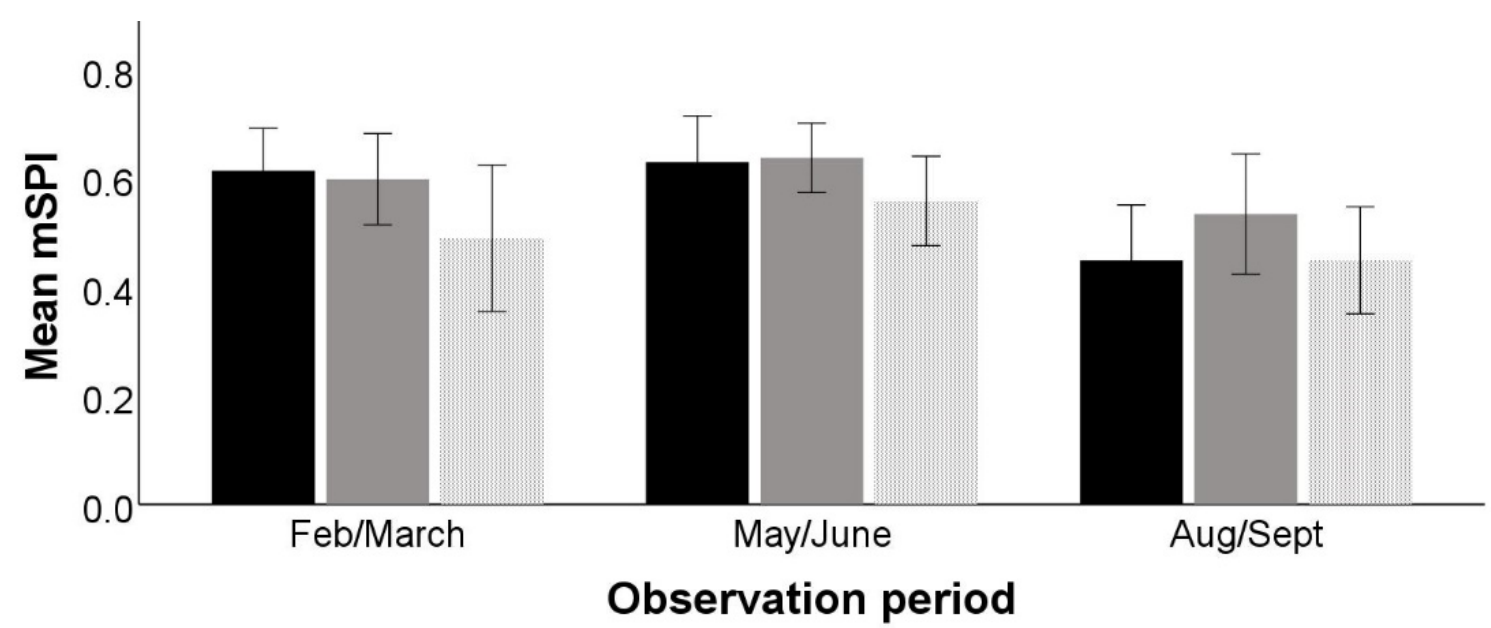

Figure 2. Modified spread of participation indices for the three time periods (black = AM, grey = midday, and dotted $=$ PM) across the three observation periods (February-March, May-June, August-September). The figure shows a decrease in mSPI value across all time periods in the final observation period. Error bars represent the standard error of the mean.

Post-hoc comparison tests showed a significant difference (mean difference $=0.131$, $\mathrm{SE}=0.032, p=0.015$ ) in mSPI between the 2nd and 3rd observation periods, May-June and August-September, indicating that resources were significantly more evenly used in the last observation period.

There was a significant difference between observation periods in use of the resources $\mathrm{BN}\left(\chi^{2}{ }_{2}=8.4 ; p=0.0151\right) ; \mathrm{CB}\left(\chi^{2}{ }_{2}=8.2 ; p=0.0169\right) ;$ and $\mathrm{W}\left(\chi^{2}{ }_{2}=6.5 ; p=0.0388\right)$. There was no significant difference in proportion of use for the other resources available (Table 1 ).

Table 1. Friedman test for repeated measures results, showing a significant different in use of the resources BN, CB, and W between time periods. Significant results are represented by an asterisk.

\begin{tabular}{ccc}
\hline \multirow{2}{*}{ Resource } & $\begin{array}{c}\text { Friedman Test for Repeated Measures Result } \\
\boldsymbol{\boldsymbol { } ^ { 2 }}{ }^{2}\end{array}$ & 0.641 \\
BB & 0.889 & $0.0151^{*}$ \\
BN & 8.389 & $0.0169^{*}$ \\
CB & 8.167 & 0.0798 \\
CN & 5.056 & 0.5899 \\
S & 1.056 & $0.0388^{*}$ \\
W & 6.500 & \\
\hline
\end{tabular}

The lizards in the 3rd observation period had increased use of the resources water body and branches outside of the bask zone. Use of the cork areas within the bask zones decreased (Figure 3).

All study animals increased in weight and subsequent body size throughout the study. The animals increased in weight by between $10.7-14.9 \mathrm{~g}$, equating to a $68-78 \%$ body weight increase over the study. Growth rate was linear, with no peaks in rapid growth between or within observation periods. 
February/March
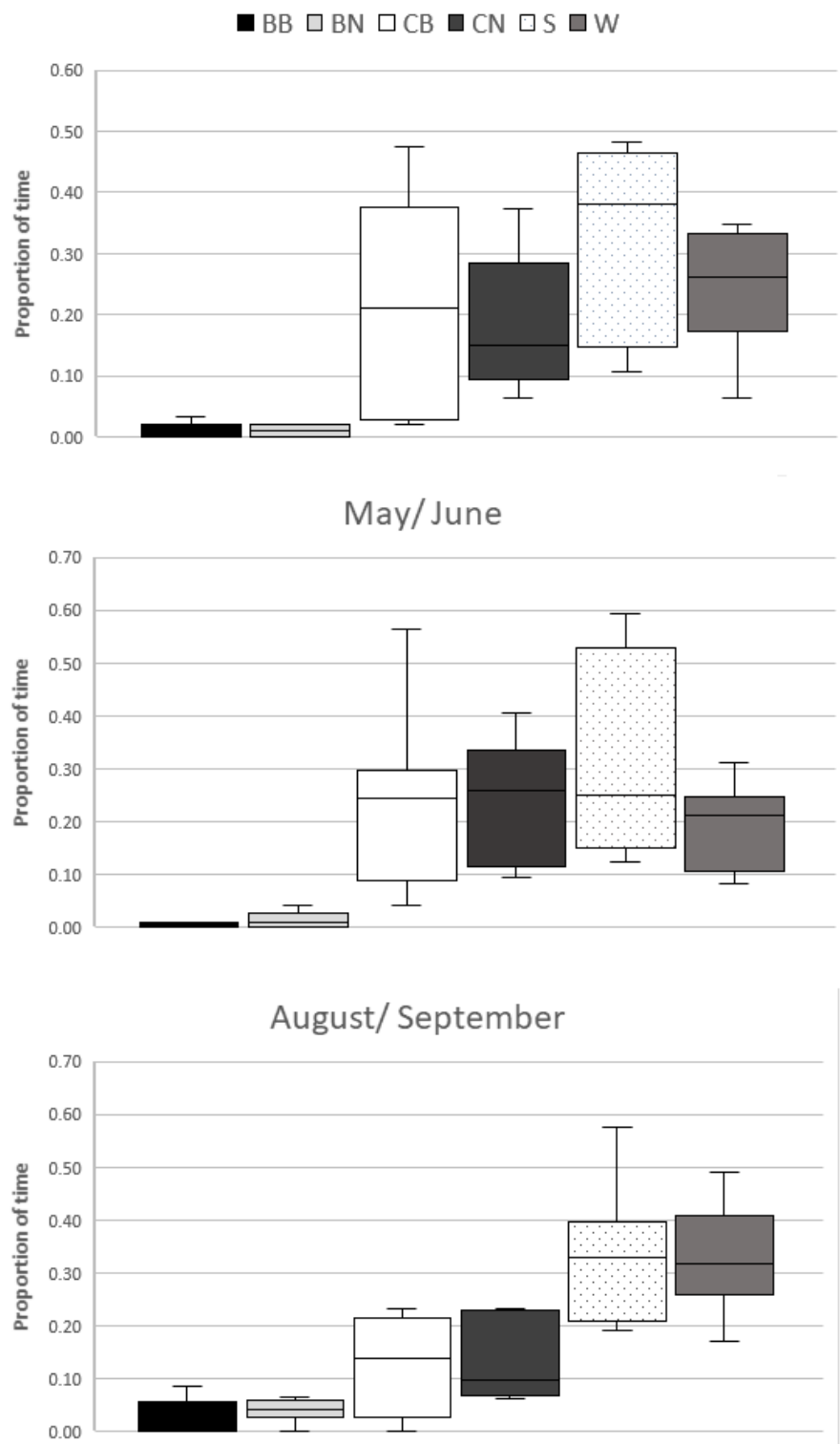

Figure 3. Proportion of time spent in each resource zone, comparing between observation periods; February-March, May-June, and August-September. BB = branches within the bask zone, $\mathrm{BN}=$ branches outside of the bask zone, $\mathrm{CB}=$ areas of the cork land within the bask zone, $\mathrm{CN}=$ cork land areas outside of the bask zone, $\mathrm{S}=$ shorelines, including the cork and branches where these meet the water body, $\mathrm{W}=$ water body.

\section{Discussion}

This study supports ontogenetic shifts in Shinisaurus c. crocodilurus, as seen in several other lizard species [22,23], suggesting implications for husbandry practitioners to cater for potentially age-specific resource requirements. Overall, the lizards utilised all resources in the enclosure more evenly, both spatially and thermally, as they aged. They additionally showed an increase in the use of more exposed resources and an increase in perch heights, reflecting changes in wild microhabitat use over the same age range (approximately 7-9 months) $[15,17]$, between the 2nd and 3rd observation period in the present study.

A significant difference in the evenness of enclosure use, shown by the Friedman test results on the mSPI values, occurred between the second and final sampling period, 
suggesting that as the animals age and/or increase in size, resources are more equally exploited. Age and consequent body size increase may alter an animal's resource use, as this influences the behavioural and physiological strategies the animals may employ, such as predator avoidance or thermoregulation [24]. The physiology of an ectothermic animal influences the time spent within resource areas: larger individuals of a lizard species have an increased capacity for retaining heat through thermal inertia and thus may perform less shuttle heliothermy [25], tending to maintain their preferred body temperature through more subtle behavioural strategies such as mouth gaping and microhabitat selection [26-28]. Recent work indicates that captive $S$. c. crocodilurus thermoregulate by altering habitat use, though overall the species has a weak propensity for accurate thermoregulation [29]. The juvenile lizards in this study increased their use of the water body and decreased use of the cork surface within the bask zone over the study period, underscoring the importance of providing varied and complex microhabitats to provide opportunities for behavioural thermoregulation. All the lizards increased in weight and corresponding body size, thus the simultaneously increasing thermal inertia in line with their greater mass may have allowed these animals to spend more time in cooler areas of the enclosure, such as the water body. Wild juvenile whiptail lizards spend more time in warmer microhabitats than adults, as they are at lower risk of overheating than larger conspecifics that may lose heat less readily as critical thermal limits for body temperature approach [19], which could theoretically also explain the results we observed in S. crocodilurus.

Overall resource occupancy became more uniform and there was a significant increase in the proportionate resource use of branches outside of the basking zone, which was a more exposed resource. Wild S. crocodilurus spend approximately $98.5 \%$ of the day inactive, perched above water bodies or within hides, with adults in general occupying perches and shelters on land rather than water [30]. Additionally, adult S. c. vietnamensis were found to favour higher perches than juveniles $[15,17]$. Over the study period the lizards showed a significant increase in their use of branches outside of the bask zone and reduced use of the cork land within the bask area, indicating a change in preference towards higher perches, suggesting captive animals undergo the same shift in microhabitat preferences as wild animals (with adults favouring higher perches). However, the water resource was utilised significantly more than other resources, contrary to wild adults' preferences of favouring branches and land areas over water bodies, but the physiology and thermoregulation of these specific study lizards may have impacted this. Wild Shinisaurus c. crocodilurus were found to prevent overheating in the summer by staying in the water and switched to greater branch use in the autumn to seek their optimal thermal gradient $[28,29]$. This species also goes through brumation during the winter months, which would impact activity budgets [12]. However, in this study the ambient and basking temperatures remained consistent, with no extreme seasonal variation throughout the data collection period.

It is also noted the species can spend $33 \%$ of the day in burrows (sinkholes, tree holes, and rock crevices) with high-concealment from vegetation, shielded from direct sunlight, with high-humidity, but not submerged in water [17,31]. It is unknown if the time spent in refugia differs between wild adults and juveniles. An increase in the use of more exposed areas by animals in this study, conflicting with wild observations, could indicate a habituation to their environment and perceived threats, for example, keepers [32]. Putative habituation may also be caused by familiarity with the enclosure and available resources, or boldness caused by an increase in size and less perceived vulnerability to predation [33,34]. In anecdotal support of the first explanation, all study lizards lost tonic immobility present from birth within 4 months of routine interactions with keepers.

There was a marginally non-significant difference $(p=0.077)$ in mSPI for time period. Like their wild counterparts this suggests that for lizards in this study there was some influence of time, with increased activity at certain periods, e.g., upon waking, but they were mostly inactive for large proportions of the day [17]. The small sample size, a common constraint of non-model species in zoo research, may have limited our ability to detect 
effects; however, in the present work we treated this as a non-significant effect to avoid a Type 1 error.

The effect of sex on resource use is unknown. All lizards in this study were unsexed and under the age of maturity. Field observations on habitat use did not distinguish sex; however, no obvious separation of niches was recorded. Therefore, it was unlikely that the sex of the study lizards had a significant effect on changes in resource use.

This study does indicate a change in resource use and utilisation corresponding with an increase in age, which may reflect adult resource budgets. In the wild, S. crocodilurus reach maturity at 3-4 years old [17,35]. This study suggests an ontogenetic shift early in the development of captive juveniles, starting at between 7 and 9 months old. Prolonged sampling would be useful to examine if changes in resource use occur up until maturity or if adult preferences are developed and maintained from a young age. This could also be compared against wild data to examine if captive animals mature in their resource use and microhabitat selection at different rates to their wild counterparts, which could have implications for enclosure design provision and conservation management. As this study was limited to a single cohort of animals, and as enclosure size was necessarily adjusted during the study (albeit with relative resource proportions maintained), there may be a confounding or interactive effect between these variables. Consequently, some caution must be exercised in attributing variation purely to lizard age, although key variables in this study were adequately controlled to do so with some confidence. We were able to control for the effect of season by using a climate-controlled room in which parameters were maintained at fixed values throughout the study. Our sampling protocol was also constrained by the practicalities of collecting data alongside running a zoo department, and so the AM, midday, and PM observation windows were relatively broad. Shinisaurus crocodilurus activity is naturally low [17], so collected data points are likely representative of the observation windows, but a finer scale data collection would be beneficial to identify more subtle patterns. Provision of a suitable habitat is one of the five welfare freedoms and a requirement of zoological institutions in many countries [36,37]. To provide a high standard of welfare, enclosure designs may need to be evaluated to provide adequate access to key resources throughout an animal's lifetime, adapting for changes in resource needs and preferences. This is of particular importance in mixed age groups, where the welfare needs of the adults may be unwittingly prioritised over juveniles.

Author Contributions: Conceptualization, K.C.C.; methodology, K.C.C. and C.J.M.; formal analysis, C.J.M.; investigation, K.C.C.; data curation, K.C.C. and C.J.M.; writing-original draft preparation, K.C.C.; writing-review and editing C.J.M., D.K., J.J.H. and B.T.; supervision, C.J.M.; project administration, K.C.C. All authors have read and agreed to the published version of the manuscript.

Funding: This research received no external funding.

Institutional Review Board Statement: Ethical review and approval were waived for this study, due to only naturally occurring behaviours being recorded during routine husbandry.

Informed Consent Statement: Not applicable.

Data Availability Statement: The data presented in this study are available on request from the corresponding author. The data are not publicly available due to institutional data sharing policies.

Acknowledgments: We thank all members of the Herpetology team at ZSL London Zoo who assisted in the husbandry of the animals in this work and inputted into the data collection; in addition to the authors, Francesca Servini, Joe Capon, Unnar Ævarsson, and Charlotte Ellis, and to Lewis Rowden for guidance and project administration.

Conflicts of Interest: The authors declare no conflict of interest. 


\section{References}

1. Hill, S.P.; Broom, D.M. Measuring zoo animal welfare: Theory and practice. Zoo Biol. Publ. Affil. Am. Zoo Aquar. Assoc. 2009, 28, 531-544. [CrossRef] [PubMed]

2. Ross, S.R.; Schapiro, S.J.; Hau, J.; Lukas, K.E. Space use as an indicator of enclosure appropriateness: A novel measure of captive animal welfare. Appl. Anim. Behav. Sci. 2009, 121, 42-50. [CrossRef]

3. Kolanek, A.; Bury, S.; Turniak, E.; Szymanowski, M. Age-Dependent Utilization of Shelters and Habitat in Two Reptile Species with Contrasting Intraspecific Interactions. Animals 2019, 9, 995. [CrossRef]

4. Ebenman, B. Niche differences between age classes and intraspecific competition in age-structured populations. J. Theor. Biol. 1987, 124, 25-33. [CrossRef]

5. Toft, C.A. Resource partitioning in amphibians and reptiles. Copeia 1985, 1-21. [CrossRef]

6. Alberts, A.C. Dominance hierarchies in male lizards: Implications for zoo management programs. Zoo Biol. 1994, 13, 479-490. [CrossRef]

7. Sinervo, B.; Adolph, S.C. Thermal sensitivity of growth rate in hatchling Sceloporus lizards: Environmental, behavioral and genetic aspects. Oecologia 1989, 78, 411-419. [CrossRef]

8. Phillips, J.A.; Alberts, A.C.; Pratt, N.C. Differential resource use, growth, and the ontogeny of social relationships in the green iguana. Physiol. Behav. 1993, 53, 81-88. [CrossRef]

9. Angilletta, M.J., Jr.; Hill, T.; Robson, M.A. Is physiological performance optimized by thermoregulatory behavior? A case study of the eastern fence lizard, Sceloporus undulatus. J. Therm. Biol. 2002, 27, 199-204. [CrossRef]

10. Horváth, G.; Mészáros, B.; Urszán, T.J.; Bajer, K.; Molnár, O.; Garamszegi, L.Z.; Herczeg, G. Environment-dependence of behavioural consistency in adult male European green lizards (Lacerta viridis). PLoS ONE 2017, 12, e0187657. [CrossRef]

11. Loughman, Z.J. Utilization of Natural History Information in Evidence based Herpetoculture: A Proposed Protocol and Case Study with Hydrodynastes gigas (False Water Cobra). Animals 2020, 10, 2021. [CrossRef] [PubMed]

12. Van Schingen, M.; Le, M.D.; Ngo, H.T.; Pham, C.T.; Ha, Q.Q.; Nguyen, T.Q.; Ziegler, T. Is there more than one Crocodile Lizard? An integrative taxonomic approach reveals Vietnamese and Chinese Shinisaurus crocodilurus represent separate conservation and taxonomic units. Der Zool. Gart. 2016, 85, 240-260. [CrossRef]

13. Gao, J.; Li, Q.; Wang, Z.; Zhou, Y.; Martelli, P.; Li, F.; Xiong, Z.; Wang, J.; Yang, H.; Zhang, G. Sequencing, de novo assembling, and annotating the genome of the endangered Chinese crocodile lizard Shinisaurus crocodilurus. GigaScience 2017, 6, gix041. [CrossRef] [PubMed]

14. Huang, C.M.; Yu, H.; Wu, Z.J.; Li, Y.B.; Wei, F.W.; Gong, M.H. Population and conservation strategies for the Chinese crocodile lizard (Shinisaurus crocodilurus) in China. Anim. Biodivers. Conserv. 2008, 31, 63-70.

15. Van Schingen, M.; Bernardes, M.; Hecht, V.; Bonkowski, M.; Ziegler, T. Current status of the Crocodile Lizard Shinisaurus crocodilurus Ahl, 1930 in Vietnam with implications for conservation measures. Rev. Suisse Zool. 2014, 121, 425-440.

16. Nguyen, T.Q.; Hamilton, P.; Ziegler, T. Shinisaurus crocodilurus. The IUCN Red List of Threatened Species 2014: E.T57287221A57287235. Available online: https://www.iucnredlist.org/species/57287221/57287235b (accessed on 31 May 2021).

17. Ziegler, T.; Van Schingen, M.; Rauhaus, A.; Dang, P.H.; Pham, D.T.K.; Pham, C.T.; Nguyen, T.Q. New insights into the habitat use and husbandry of crocodile lizards (Reptilia: Shinisauridae) including the conception of new facilities for Vietnamese crocodile lizards Shinisaurus crocodilurus vietnamensis in Vietnam and Germany. Int. Zoo Yearb. 2019, 53, 250-269. [CrossRef]

18. Durtsche, R.D.; Gier, P.J.; Fuller, M.M.; Lutterschmidt, W.I.; Bradley, R.; Meier, C.K.; Hardy, S.C. Ontogenetic variation in the autecology of the greater earless lizard Cophosaurus Texanus. Ecography 1997, 20, 336-346. [CrossRef]

19. Paulissen, M.A. Ontogenetic and seasonal shifts in microhabitat use by the lizard Cnemidophorus sexlineatus. Copeia 1988, 1021-1029. [CrossRef]

20. Image J Image Processing and Analysis in Java. Available online: https:/ /imagej.nih.gov/ij/ (accessed on 9 July 2021 ).

21. Plowman, A.B. A note on a modification of the spread of participation index allowing for unequal zones. Appl. Anim. Behav. Sci. 2003, 83, 331-336. [CrossRef]

22. Stamps, J.A. The relationship between ontogenetic habitat shifts, competition and predator avoidance in a juvenile lizard (Anolis aeneus). Behav. Ecol. Sociobiol. 1983, 12, 19-33. [CrossRef]

23. Nemes, S.; Vogrin, M.; Hartel, T.; Öllerer, K. Habitat selection at the sand lizard (Lacerta agilis): Ontogenetic shifts. North-West. J. Zool. 2006, 2, 17-26.

24. Sagonas, K.; Meiri, S.; Valakos, E.D.; Pafilis, P. The effect of body size on the thermoregulation of lizards on hot, dry Mediterranean islands. J. Therm. Biol. 2013, 38, 92-97. [CrossRef]

25. Meek, R. Reptiles, thermoregulation, and the environment. Testudo 2016, 4, 56-78.

26. Asplund, K.K. Body size and habitat utilization in whiptail lizards (Cnemidophorus). Copeia 1974, 695-703. [CrossRef]

27. Ellis, H.I. Field observations of cooling rates of Galapagos land iguanas (Conolophus subcristatus). Comp. Biochem. Physiol. Part A Physiol. 1987, 59, 205-209. [CrossRef]

28. Harlow, H.J.; Purwandana, D.; Jessop, T.S.; Phillips, J.A. Size-related differences in the thermoregulatory habits of free-ranging Komodo dragons. Int. J. Zool. 2010. [CrossRef]

29. Yang, Y.J.; Zeng, Z.G.; Xing, K.F.; Li, S.R.; Yang, C.S.; Du, W.G. Behavioural thermoregulation by the endangered crocodile lizard (Shinisaurus crocodilurus) in captivity. J. Therm. Biol. 2020, 93, 102731. [CrossRef]

30. Zollweg, M.; Kühne, H. Krokodilschwanzechsen-Shinisaurus Crocodilurus; Natur und Tier Verlag: Münster, Germany, 2013. 
31. Zhao, J.Y.; Zhang, Y.X.; Lang, D.Y. Ecology of Chinese crocodilian lizard in Burrow. Sichuan J. Zool. 2006, 12, $261-263$.

32. Hosey, G.; Melfi, V.A. Us and Them: Human-Animal Interactions as Learning Events. In Zoo Animal Learning and Training; John Wiley \& Sons Ltd.: New York, NY, USA, 2020; pp. 167-181.

33. Blumstein, D.T. Habituation and sensitization: New thoughts about old ideas. Anim. Behav. 2016, 120, 255-262. [CrossRef]

34. Kelleher, S.R.; Silla, A.J.; Dingemanse, N.J.; Byrne, P.G. Body size predicts between-individual differences in exploration behaviour in the southern corroboree frog. Anim. Behav. 2016, 129, 161-170. [CrossRef]

35. Wang, Z.X.; Wu, Z.J.; Chen, L.; Yu, S.; Yu, H.; Huang, C.H.; Jiang, J. Effects of pregnancy and ages on temperature selection and resting metabolic rates in Chinese Crocodile Lizard, Shinisaurus crocodilurus. J. Guangxi Norma Univ. Nat. Sci. Ed. 2009, $27,80-83$.

36. Mäekivi, N. Freedom in captivity: Managing Zoo animals according to the 'five freedoms'. Biosemiotics 2018, 11, 7-25. [CrossRef]

37. Secretary of State's Standards of Modern Zoo Practice; DEFRA: London, UK, 2000. 